\title{
Evaluation and improvement of the quality of Senegalese reinforcing steel bars produced from
} scrap metals

Mamadou Babacar NDIAYE ${ }^{1,2}$, Sandrine BEC ${ }^{1 *}$, Bernard COQUILLET $^{1}$, Ibrahima Khalil CISSE ${ }^{2}$

${ }^{1}$ Laboratoire de Tribologie et Dynamique des Systèmes, UMR 5513, Ecole Centrale de Lyon, Ecully, France

${ }^{2}$ Laboratoire de Matériaux, Mécanique et Hydraulique, Ecole Supérieure Polytechnique, Thiès, Sénégal

* Corresponding author: Tel +334721862 70; Fax +33478433383

E-mail address : sandrine.bec@ec-lyon.fr (S. Bec).

\begin{abstract}
Senegalese reinforcing steel bars manufactured from scrap steel exhibit poor welding and bending abilities. The purpose of this study is to evaluate and to correlate the geometrical, mechanical and metallurgical characteristics of these steel bars in order to identify possible causes for their breaking during bending. The relevance of the technical specification defined by the manufacturer and its ability to lead to products of good quality will be discussed. A diagram is proposed to control the expected quality of reinforcing bars from a simple Vickers hardness measurement before the final forming stage.
\end{abstract}

Keywords: ferrous metals and alloys (A), recycling (C), mechanical properties (E)

\section{Introduction}

In civil engineering, concrete structures need to be strengthened by reinforcing steel bars. In developing countries, construction is continuously growing (Fig. 1) but importing steel is expensive. That is why, metal recycling is significantly developed. In Africa, a lot of objects or materials are recycled, including metals, in order to produce convenience goods. For instance, in Senegal, most of the kitchen utensils used by family households are made of scrap aluminium alloys by traditional casting. But economical concern is not the only reason for developing recycling. Thanks to lower energy consumption, it contributes to preserve natural resources (wood, raw materials...).

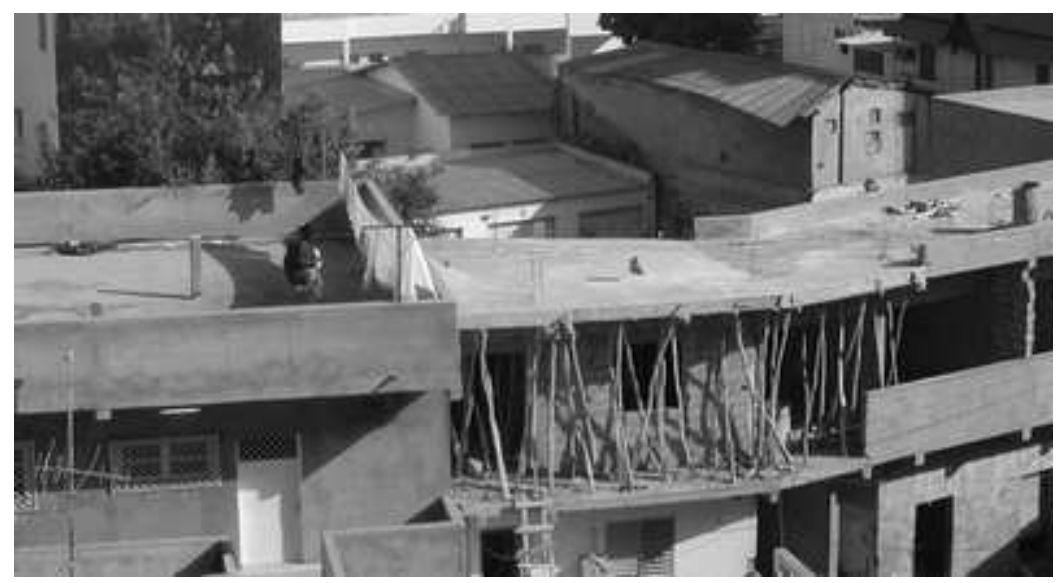

Fig. 1. Construction of new buildings in Dakar.

Concerning reinforcing steel bars, only one manufacturer, named SOSETRA, is specialized in this activity all over Senegal. SOSETRA is located near Dakar and produces about 4000 tons/year of reinforcing steel bars. This quantity is small compared to the steel industry in Ghana which recycles about $80 \%$ steel scrap, estimated to be 80000 tons per year, for the production of structural and 
reinforcing steel [1]. This is both due to the difficulty in scrap steel supply in Senegal and to the impossibility in processing cast iron because of inadequate manufacturing method.

Vehicles and machine metal parts are melted in an electric furnace. During this operation, the chemical composition of the steel is controlled. At the end of the melting process, the steel is deoxidized by silico-manganese additions, then cleaned and cast to produce steel bars which are cut at the desired length with an oxy-acetylenic blow torch, before cooling in calm air. After heating to 1100 ${ }^{\circ} \mathrm{C}$ during one hour, these bars are hot rolled to produce reinforcing bars.

In order to respect the building standards of civil engineering, the reinforcing steel bars must adhere to some specifications such as minimal value of nominal yield strength, weldability, elongation at rupture ... In Senegal, as there isn't any national standard governing the mechanical properties and the manufacturing of reinforcing steel bars, the Senegalese agency for standardization refers to the French or European standards, respectively NF A35-016 and NF EN10080. The steel plant itself has defined its own standards, which fix the chemical composition (table 1) in order to produce reinforcing steels bars with $400 \mathrm{MPa}$ minimum yield strength calculated using the nominal diameter. But the chemical composition of the SOSETRA products is significantly different from the standard Fe E 40 (NF EN 10080) (table 2), which has similar mechanical properties. The carbon content of the Senegalese steel intended to be used for reinforcing bar manufacturing is too high. This is both due to the steel scrap quality which includes a lot of high carbon steel and to the absence of metal refining stage during the process.

\begin{tabular}{lcccccc}
\hline Elements & $\mathrm{C}$ & $\mathrm{Mn}$ & $\mathrm{Si}$ & $\mathrm{P}$ & $\mathrm{S}$ & $\mathrm{Cr}$ \\
\hline Weight \% min. & 0.30 & 0.50 & 0.10 & $/$ & $/$ & $/$ \\
Weight \% max. & 0.60 & 0.70 & 0.25 & 0.055 & 0.055 & 0.5 \\
\hline
\end{tabular}

Table 1. SOSETRA standards for the chemical composition of steel intended to be used for reinforcing bar manufacturing

\begin{tabular}{lccccc}
\hline Elements & $\mathrm{C}$ & $\mathrm{P}$ & $\mathrm{S}$ & $\mathrm{Cu}$ & $\mathrm{Ni}$ \\
\hline Weight \% max. & 0.24 & 0.055 & 0.055 & 0.085 & 0.013 \\
\hline
\end{tabular}

Table 2. Fe E 40 standards (NF EN 10080) for the chemical composition of steel intended to be used for reinforcing bar manufacturing

The European standards also specify a minimum elongation before failure and a tolerance on the shape of the reinforcing bars through a tolerance value for the mass per unit length $\Delta X / X$, which is not considered in the Senegalese local production. This tolerance is equal to $\pm 10 \%$ for NF A35-016and \pm $4.5 \%$ for NF EN 10080 .

For all these reasons, the locally milled reinforcing bars are of unequal quality, often too much brittle to resist to bending.

In this study, our purpose is to point out the relevant parameters related to the quality of $10 \mathrm{~mm}$ nominal diameter Senegalese reinforcing steel bars and to study their correlation. In a first step, the origin of the quality problems raised up by the users will be investigated. Then, the relevance of the specifications used by the manufacturer will be evaluated and discussed. Finally, a simple solution will be proposed to permit to control the ability of the steel to produce reinforcing bars with given characteristics.

\section{Method}

In this work, it was chosen to study $10 \mathrm{~mm}$ nominal diameter reinforcing steel bars, which constitute the main production of the plant. Samples have been collected over one year from five different melts (labelled A, B, C, D and E) whose chemical compositions are representative of the whole production. Their chemical compositions were measured by spectrometry. One billet has been 
selected from each melt. After rolling, the length of the billet is 127 times its initial length (from $2.6 \mathrm{~m}$ to $330 \mathrm{~m}$ ) and the reinforcing bars form 3 meters diameters coils. The samples, $17 \mathrm{~cm}$ length, were cut on different parts of the coils, located at the beginning, in the middle and at the end of the coil (Fig. 2) respectively labelled as $\mathrm{X}-1, \mathrm{X}-2, \mathrm{X}-3$ ( $\mathrm{X}$ being the melt label).

Optical and scanning electronic microscopes have been used to examine the microstructure, and to identify and analyse the inclusions in the metal.

Tension tests have been performed on the reinforcing bar samples with an INSTRON apparatus

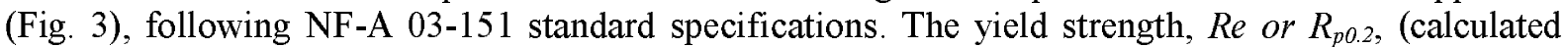
with the measured initial diameter, $d$ ) and the nominal yield strength, $f_{e}$ (calculated with the nominal diameter, $\Phi)$ were determined. The percentage of elongation at failure $(A \%)$ was measured on each sample. Vickers hardness measurements under $1 \mathrm{~kg}$ load $\left(H V_{1}\right)$ have been performed on sample cross sections, following EN ISO 6507 standard specifications. The relative difference between measured and expected mass per unit length, $\Delta X / X$, was calculated.

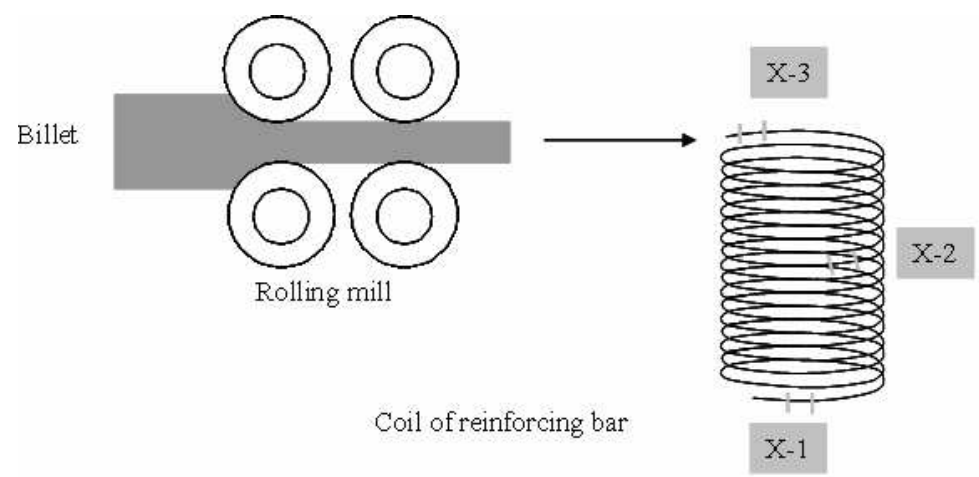

Fig. 2. Location of the samples on the coil.

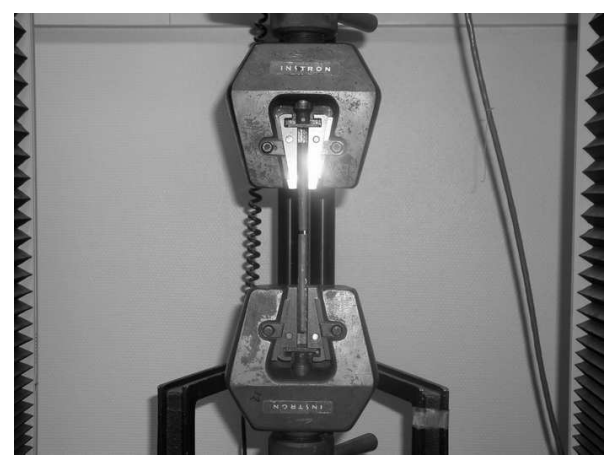

Fig. 3. Picture of the set-up used for traction tests.

\section{Results}

\subsection{Steel composition}

The chemical composition of the five studied melts is given in table 3 . All are in conformity with the standards defined by the manufacturer concerning $\mathrm{C}, \mathrm{Si}$ and $\mathrm{S}$ contents. The Mn content of sample A and the $P$ content of sample D are too high.

\begin{tabular}{llllll}
\hline Elements (weight \%) & $\mathrm{C}$ & $\mathrm{Mn}$ & $\mathrm{Si}$ & $\mathrm{P}$ & $\mathrm{S}$ \\
\hline $\mathrm{A}$ & 0.42 & 0.76 & 0.14 & 0.016 & 0.012 \\
$\mathrm{~B}$ & 0.38 & 0.67 & 0.24 & 0.020 & 0.011 \\
$\mathrm{C}$ & 0.44 & 0.57 & 0.13 & 0.019 & 0.011 \\
$\mathrm{D}$ & 0.30 & 0.56 & 0.11 & 0.23 & 0.014 \\
$\mathrm{E}$ & 0.35 & 0.53 & 0.12 & 0.019 & 0.015 \\
\hline
\end{tabular}

Table 3. Chemical composition of the tested steel samples

\subsection{Steel microstructure}

The microstructure of all samples consists of ferrite (clear areas) and pearlite (dark areas). In each melt, grain diameters are similar (about $10 \mu \mathrm{m}$ ), except in E melt where they are significantly smaller and exhibit a Widmanstaetten pattern (Fig. 4).

Surface decarburization is quasi-systematically observed on each sample (Fig. 5a). Until a distance of about $500 \mu \mathrm{m}$ from the surface, the microstructure becomes almost fully ferritic. This indicates that, 
near the surface, the carbon content value is equal to its maximum solubility in the ferritic phase (ie approximately inferior to $0.002 \%$ in weight).

This decarburization is confirmed by hardness measurements performed on cross sections, and regularly spaced along a diameter (Fig. 5b). A decrease of about $70 \mathrm{HV}_{1}$ has been measured near the surface.

Other defects such as oxide or sulphur inclusions and laps have also been observed (example of inclusion on Fig. 6).

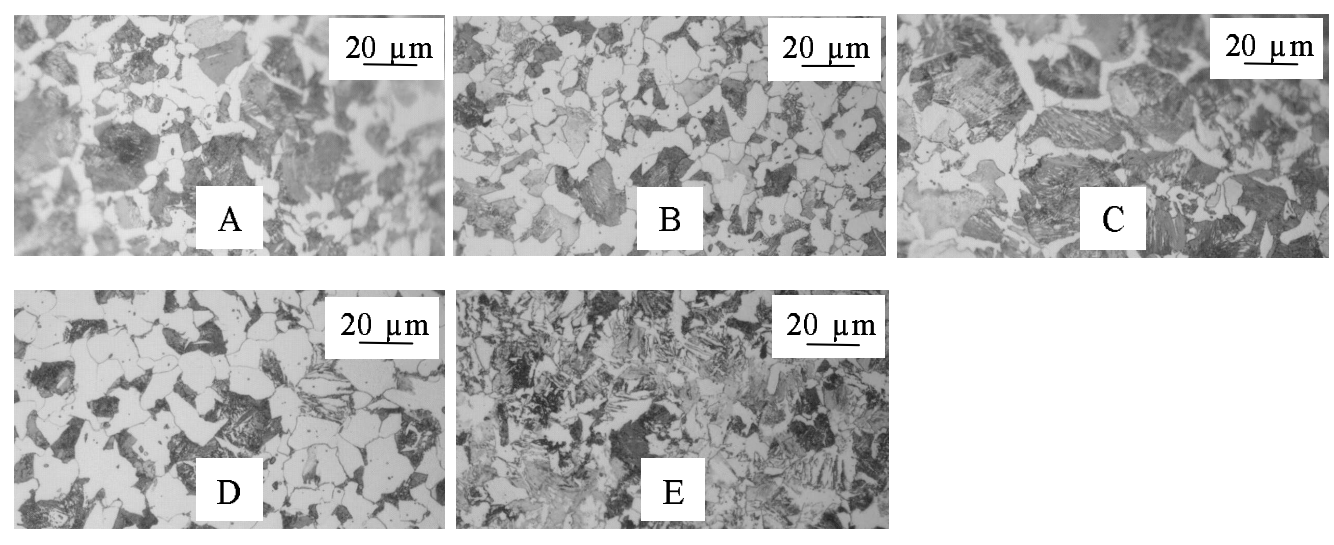

Fig. 4. Microstructure of the steel samples, mainly composed of ferrite (clear areas and pearlite (dark areas).

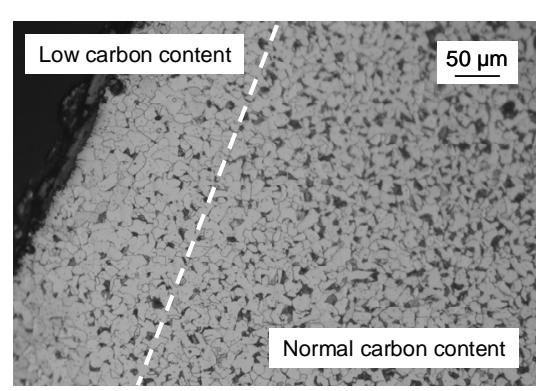

(a)

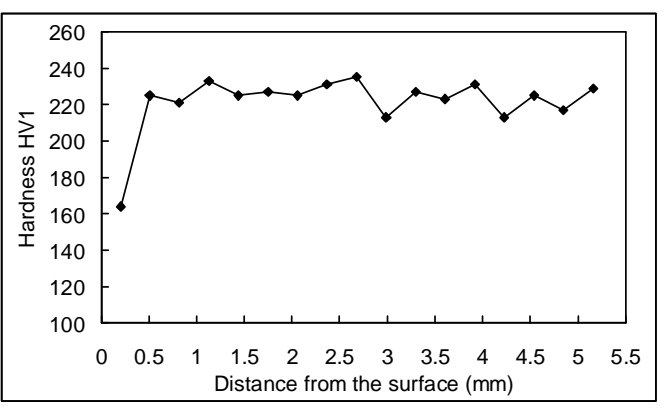

(b)

Fig. 5. Illustration of surface decarburization (a) optical observation of the microstructure near surface sample, (b) Vickers hardness measurement on a cross section.

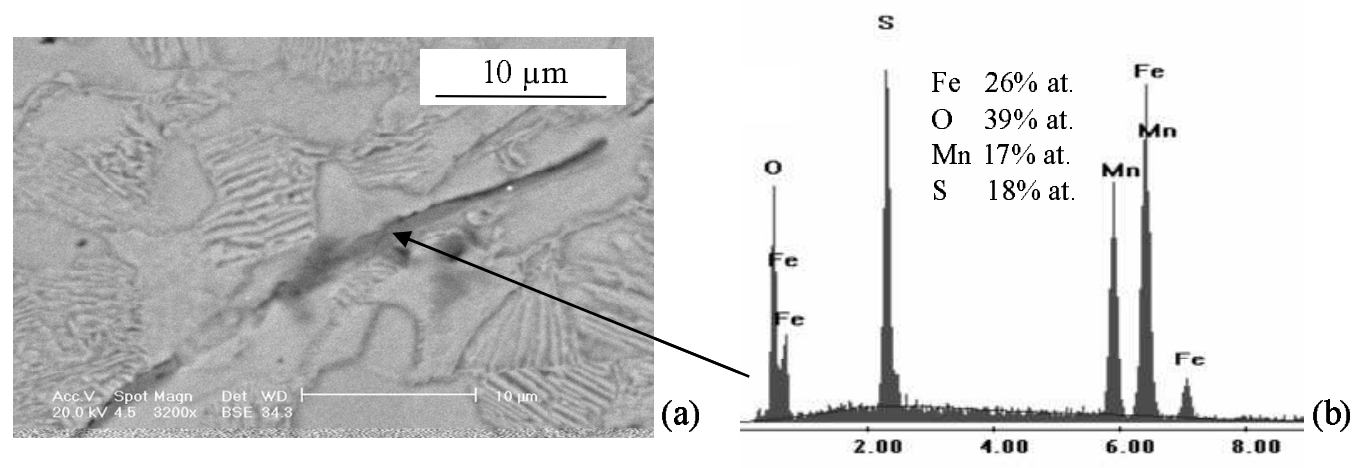

Fig. 6. Example of inclusion, (a) SEM observation, (b) corresponding EDX analysis. 


\subsection{Mechanical properties}

Tensile curves obtained in our tests were of two different types (Fig. 7a and 7b):

- Typical force-elongation curves obtained on samples from A, B, C and D melts exhibit an initial linear elastic portion before a yield plateau which is characteristic of annealed mild steels containing intersticial elements like carbon or nitrogen [2, 3]), then a strain-hardening domain followed by a stress drop just before failure.

- For samples from E melt, the yield plateau is not present. Such situation occurs in carbon steels after work-hardening or after heat treatments leading to a non equilibrium microstructure as in dual-phase steels [4]). This is confirmed by the microstructure observed on these samples.

The geometrical and mechanical properties of the tested specimens are reported in table 4 where $f_{e}$ is the nominal yield strength of the reinforcing bar calculated with the nominal bar diameter $\Phi=10$ $\mathrm{mm}, \operatorname{Re}$ or $R_{p 0.2}$ is the yield strength of the steel calculated with the measured initial bar diameter $d$, $A \%$ is the percentage of elongation at failure, $\Delta X X X$ is the relative difference between measured and expected mass per unit length and $H V_{1}$ is the Vickers hardness under $1 \mathrm{~kg}$ load.

From this table, the following conclusions can be drawn:

- the guaranteed nominal yield strength of $400 \mathrm{MPa}$ is not always respected for the tested specimens (it is lower than $400 \mathrm{MPa}$ for B-1, B-2, D-1 and D-2);

- all samples exhibit a measured initial diameter $d$ lower than the nominal value $\Phi=10 \mathrm{~mm}$. The $d$ value varies from 8.9 to $9.4 \mathrm{~mm}$. This results in too high values for $\Delta X / X$ according to the $\mathrm{NF}$ EN10080 standards which recommends a maximum value of $\pm 4.5 \%$;

- all samples exhibit sufficiently high values for $A \%$, higher than $14 \%$ which is the value given by the European standards;

- $\quad$ specimens from E melt have the highest tensile characteristics and hardness values, and E-1 exhibits the lowest values for $A \%$, just at the threshold.

\begin{tabular}{ccccccc}
\hline Samples & $\mathrm{f}_{\mathrm{e}}(\mathrm{MPa})$ & $\mathrm{d}(\mathrm{mm})$ & $\mathrm{R}_{\mathrm{e}}$ or $\mathrm{R}_{\mathrm{p} 0.2}(\mathrm{MPa})$ & $\mathrm{A} \%$ & $\mathrm{HV}_{1}$ & $\Delta \mathrm{X} / \mathrm{X}(\%)$ \\
\hline $\mathrm{A}-1$ & $445 \pm 10$ & 9 & $527 \pm 10$ & 20 & 225 & -18 \\
$\mathrm{~A}-2$ & $445 \pm 10$ & 9 & $529 \pm 10$ & 19 & 223 & -19 \\
$\mathrm{~A}-3$ & $470 \pm 10$ & 9.4 & $526 \pm 10$ & 17 & 220 & -12 \\
\hline $\mathrm{B}-1$ & $380 \pm 10$ & 8.9 & $473 \pm 10$ & 23 & 195 & -24 \\
$\mathrm{~B}-2$ & $380 \pm 10$ & 8.9 & $474 \pm 10$ & 24 & 201 & -24 \\
$\mathrm{~B}-3$ & $420 \pm 10$ & 9.3 & $479 \pm 10$ & 26 & 203 & -15 \\
\hline $\mathrm{C}-1$ & $435 \pm 10$ & 8.9 & $535 \pm 10$ & 24 & 245 & -24 \\
$\mathrm{C}-2$ & $420 \pm 10$ & 8.9 & $522 \pm 10$ & 23 & 241 & -25 \\
$\mathrm{C}-3$ & $465 \pm 10$ & 9.3 & $535 \pm 10$ & 21 & 249 & -14 \\
\hline D-1 & $365 \pm 10$ & 8.9 & $455 \pm 10$ & 26 & 200 & -26 \\
D-2 & $360 \pm 10$ & 8.9 & $450 \pm 10$ & 27 & 189 & -25 \\
$\mathrm{D}-3$ & $410 \pm 10$ & 9.2 & $460 \pm 10$ & 28 & 188 & -13 \\
\hline E-1 & $490 \pm 10$ & 9 & $601 \pm 10$ & 14 & 292 & -23 \\
E-3 & $530 \pm 10$ & 9.4 & $593 \pm 10$ & 17 & 292 & -12 \\
\hline
\end{tabular}

Table 4. Geometrical and mechanical properties of the test specimens $(\Phi=10 \mathrm{~mm})$ 

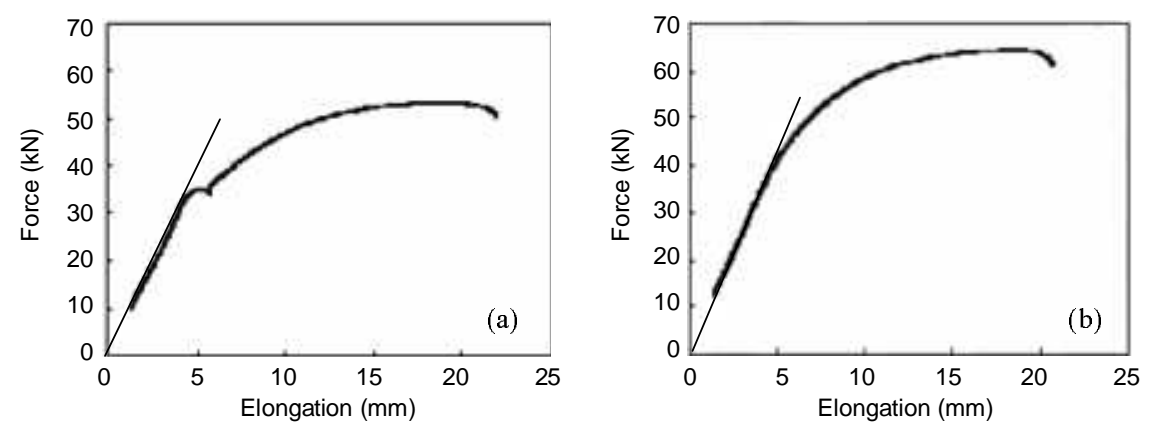

Fig. 7. Typical force-elongation curves obtained on the samples (a) with yield plateau (b) without yield plateau.

\section{Discussion}

Considering only the criterion of the manufacturer, which is a minimum value of $400 \mathrm{MPa}$ for the nominal yield strength, it can be said that the global quality of the reinforcing steel bars produced by SOSETRA is rather acceptable. However, 4 bars among the 14 tested bars are below this limit. In the following, the results will be first analyzed and linked to the quality problems that have been pointed out. Then solutions will be proposed to improve the quality of the reinforcing steel bars.

The quality of reinforcing bars is not only linked to some specific characteristics such as $\Delta X / X$ used in civil engineering but also to the quality of the material used for their manufacturing, which is the steel produced from scrap metal. These two aspects are now investigated.

\subsection{Reinforcing steel bars characteristics}

It is remarkable that the measured diameter of the reinforcing bars is always significantly lower than the expected nominal diameter of $10 \mathrm{~mm}$. This results in negative values for $\Delta X X X$. Furthermore, high values of $\Delta X / X$ were obtained, between $-12 \%$ (for A-3 and D-3 samples) and $-26 \%$ (for D-1 sample). From this point of view, all reinforcing bars do not respect NF EN 10080 or NF A35-016 standards, for which the maximum values are respectively $\pm 4.5 \%$ and $\pm 10 \%$.

Moreover, as the nominal yield strength $f_{e}$ is calculated by dividing the force supported by the bar during the tensile test by the nominal section $S_{n}\left(S_{n}=\pi \Phi^{2 / 4}\right.$ with $\left.\Phi=10 \mathrm{~mm}\right)$, its value is lower than the yield strength $R e$ or $R_{p 0.2}$ when the measured initial diameter is lower than the nominal one. That is why for the lowest values of measured diameter, obtained with B-1, B-2, D-1 and D-2 samples, the nominal yield strength does not reach the expected value of $400 \mathrm{MPa}$.

Otherwise, referring to NF A35-016 and NF EN10080 standards, all tested specimens have sufficiently high values for the percentage of elongation at failure $(A \%>14)$.

\subsection{Steel quality}

Steel quality is both related to chemical composition, as exposed in NF A35-016 and NF EN10080 standards, and to microstructure, each of them governing the mechanical properties.

\section{Role of chemical composition}

If the carbon content of the produced steel agrees with the specifications of the manufacturer $(0.3<$ $\mathrm{C} \%<0.6)$, it is rather far from the European standard $(\% \mathrm{C}<0.24)$.

The immediate consequence is that the steel yield strength exhibits high values as it varies almost proportionally to the carbon content [5]. Excepted for the specimen from E melt which has a different microstructure, this is verified for the tested specimens (data in tables 3 and 4).

Thus, the minimum value of the yield strength estimated for annealed steels is about $500 \mathrm{MPa}$ in steels containing $0.6 \% \mathrm{C}$, and $350 \mathrm{MPa}$ with $0.3 \% \mathrm{C}$ [5]. But in the case of the tested samples, the 
expected values for the tested specimens are higher, considering the steel composition and the equivalent carbon content given by the European standards NF EN 10080:

$$
\mathrm{C}_{\mathrm{eq}}=\mathrm{C} \%+(\mathrm{Mn} \%) / 6+(\mathrm{Cr} \%+\mathrm{Mo} \%+\mathrm{V} \%) / 5+(\mathrm{Ni} \%+\mathrm{Cu} \%) / 15
$$

If it permits to reach high nominal yield strength values which respect the minimum guaranteed value even with reinforcing bar diameters significantly lower than the nominal one, the drawback of high carbon content steels is their poor ductility which decreases with increasing yield strength (Fig. 8). And this is prejudicial to the use of the steel to produce reinforcing bars which are expected to resist to bending. That is why European norms have fixed a minimum limit of $14 \%$ for elongation at rupture. In this study, E-1 sample, which exhibits the highest yield strength value (Re or $R_{p 0.2}=600$ $\mathrm{MPa}$ ), reaches this threshold (see data in table 4).

We can also note that decarburisation, which has been observed on all tested bars, has a positive effect on the mechanical behaviour. It minimises brittle rupture ability in a sensitive zone, the surface, where defects like cracks and laps are located [6]. This is particularly important when the reinforcing steel bars are bent during implementation, as the maximum strain is supported near the surface where it is thus important to have a good ductility.

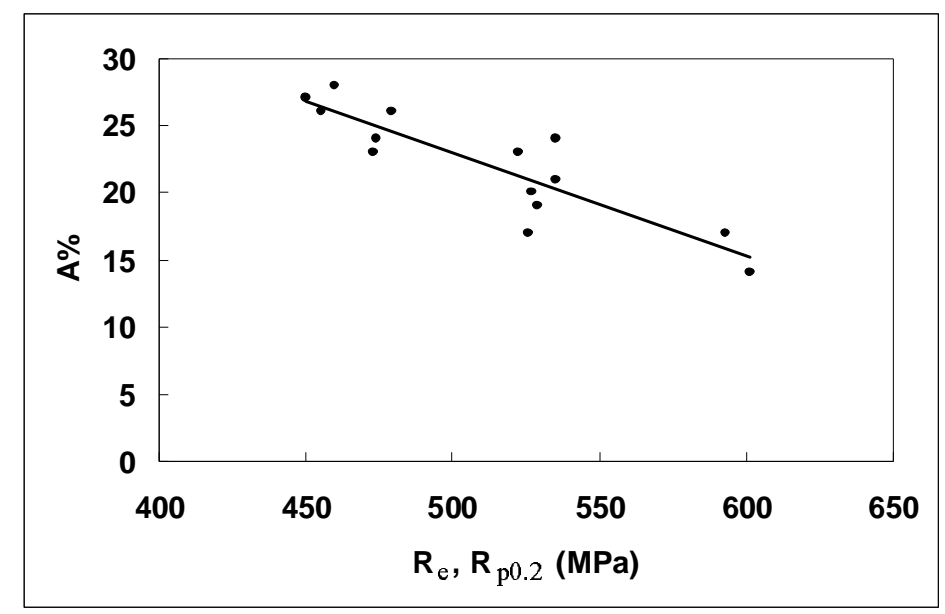

Fig. 8. Percentage of elongation at failure versus yield strength for all tested specimen.

\section{$\underline{\text { Role of microstructure }}$}

It was previously noted that $\mathrm{E}$ melt exhibits a different microstructure (Widmanstaetten pattern) and has the highest mechanical properties (hardness and yield strength).

For carbon steels, these features can be related to the cooling rate after heating [7]. To verify this hypothesis, an annealing normalisation treatment was performed on a specimen from melt $\mathrm{E}$ : the heating temperature was increased up to $850^{\circ} \mathrm{C}$ then the sample was slowly cooled in ambient air.

The obtained microstructure was quite similar to those observed on A, B, C, D melts, and different from the initial feature (Fig. 9a). This demonstrates that the specific microstructure observed for melt E can be explained by its thermal history, which should have been different from the other ones. Microhardness measurements performed on cross sections of the heat-treated specimen confirm this result as the initially high hardness values decrease after the heat-treatment to reach values in the same range as those measured on samples from melts $\mathrm{A}$ to $\mathrm{D}$ (Fig. 9b).

Finally, these results show that a single specification concerning the chemical composition cannot guarantee the quality of reinforcing steel bars. The manufacturing process, which has an influence on geometrical characteristics, must be taken into account, as well as the microstructure, which is the parameter that controls the mechanical properties. 


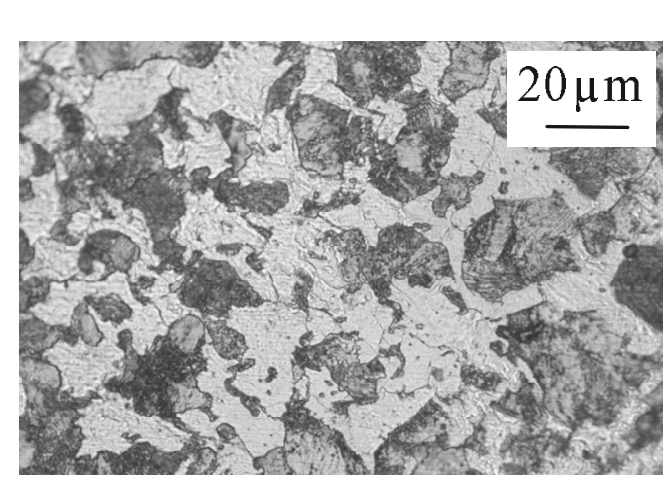

(a)

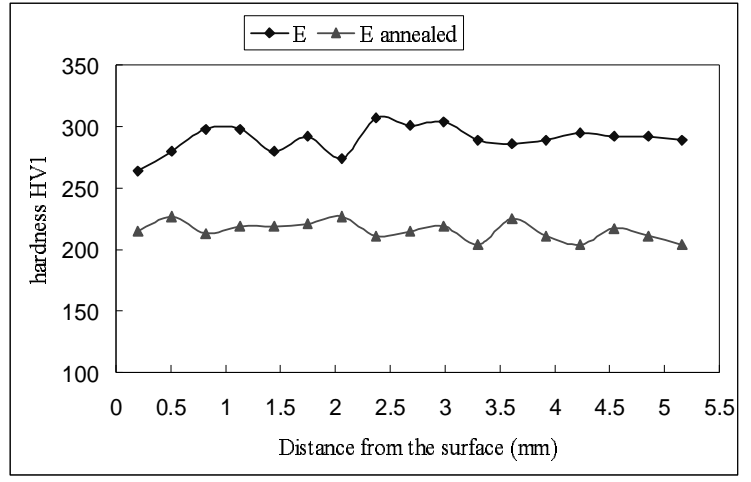

(b)

Fig. 9. Effect of annealing heat-treatment on a sample from melt $E$ : (a) optical observation of the microstructure after heat-treatment, (b) Vickers hardness measured on cross sections.

\subsection{Different ways to improve reinforcing bar quality}

Now, different ways can be proposed to increase quality. The origin of the problems encountered with the steels produced is related to too high carbon content. So carbon content must be lowered.

This could be done by decarburisation in the liquid phase, by injecting pressurized air or oxygen after melting. Such refining process is a classical stage in steel engineering named "oxygen refining", or Bessemer or Thomas refining [8].

Another way could be a decarburisation in solid phase by diffusion and oxidation of the carbon at high temperature. This has been industrially used to malleabilise white cast irons. This process, technically possible, cannot be supported by the manufacturer because the energetical cost would be too expensive.

A third possible way is to select and recycle only low carbon content steel scraps. However, this solution would inevitably lead to a drastic reduction of the produced steel quantity, since steel scrap amount is limited in Senegal.

In order to avoid heavy changes in the process, the quality of the reinforcing steel bars could be improved by checking the steel quality before use and by introducing a tolerance concerning the geometrical characteristics of the bars; possible compensation effects are then limited. From the previous results (table 4), an empirical linear relation permits to relate the yield strength of the samples and their Vickers hardness, which can be easily measured (both expressed in $\mathrm{MPa}$ ):

$$
\text { Re or } R_{p 0.2}=0.13 H V_{1}+220
$$

This relation is quite different from the one proposed by Tabor [9]: $H=3 Y$ where $\mathrm{H}$ is the Vickers hardness of the steel (expressed in $\mathrm{MPa}$ ) and $Y$ is the conventional true yield stress for a residual plastic strain of $8 \%$, corresponding to the plastic strain for Vickers indentation. From the previous tensile curves and considering the yield stress measured for a plastic strain of $8 \%$, we obtain $H=2.83$ $Y$, which is in rather good agreement with Tabor's relation.

For a given nominal diameter $\Phi$, the nominal yield stress $f_{e}$ is related to the yield strength $\operatorname{Re}$ or $R_{p 0.2}$ by the following equation, $f_{e}=\operatorname{Re}$ or $R_{p 0.2} d^{2} / \Phi^{2}$, which permits to rewrite Eq.1 as:

$$
f_{e}=\left(0.13 H V_{1}+220\right) d^{2} / \Phi^{2} \quad \text { (Eq. 2) }
$$

If we consider the tolerance value for the mass per unit length, $\Delta X / X= \pm 4.5 \%$ (NF EN10080), which can be changed into a tolerance value for the bar diameter $d$ as $\Delta X X X=2 \Delta d / d$, an empirical graph can be drawn which defines a domain for acceptable mechanical and geometrical properties to produce reinforcing bars with desired yield strength and ductility. This domain (grey area on Fig. 10) is delimited by linear relations: $\operatorname{Re}$ or $R_{p 0.2}=\left(0.13 H V_{1}+220\right)(1+1 / 2 \Delta X X)^{2}$ with $\Delta X / X= \pm 4.5 \%$. In its lower part, it is limited by the minimum guaranteed value for the nominal yield strength, $f_{e}=400$ 
$\mathrm{MPa}$ and in its upper part, it is limited by the maximum yield strength value with acceptable elongation, which is $\operatorname{Re}$ or $R_{p 0.2}=600 \mathrm{MPa}$.

This graph permits to estimate the nominal yield strength of a steel bar from a simple Vickers hardness measurement, which can be easily performed in the Senegalese industrial context. For instance, it indicates that steel with a Vickers hardness value between 120 and 290 can be used to produce $10 \mathrm{~mm}$ nominal diameter reinforcing steel bars with $f_{e}>400 \mathrm{Mpa}$, but for the softer steel, the real diameter must be equal to $10.22 \mathrm{~mm}$ to respect the specification. Or, it will possible to produce reinforcing bars with minimal nominal yield strength of $500 \mathrm{MPa}$ if the steel Vickers hardness is higher than $200 \mathrm{HV}_{1}$.

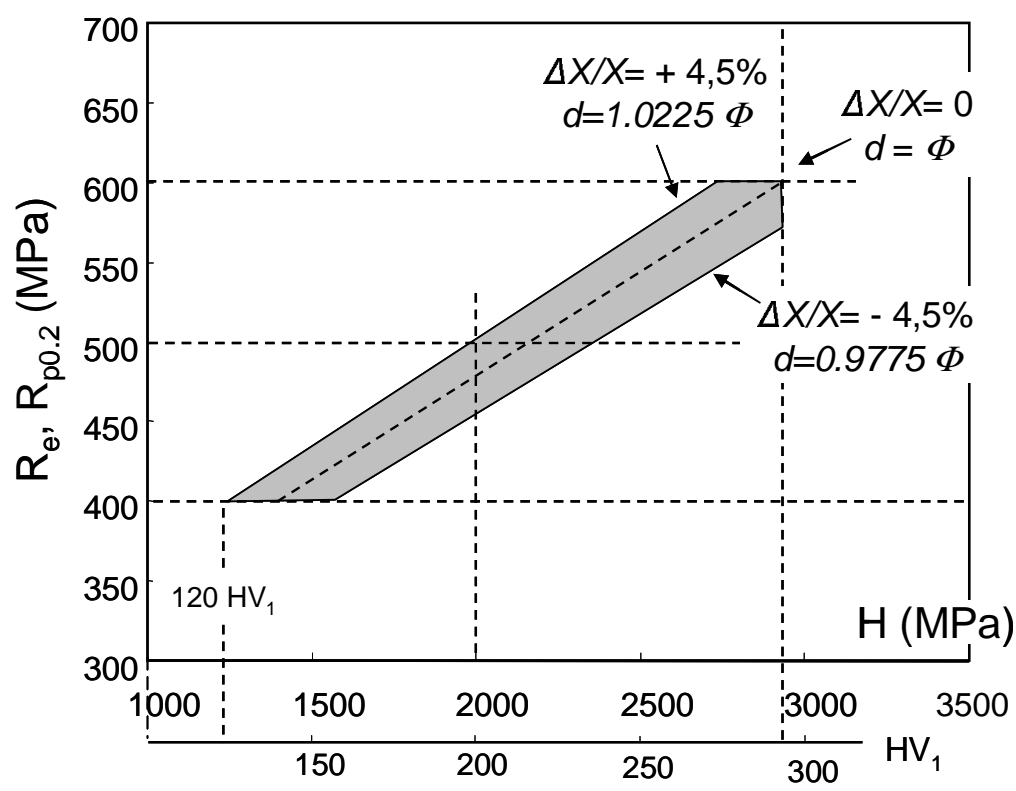

Fig. 10. Domain for acceptable mechanical and geometrical properties to produce reinforcing bars with desired yield strength and ductility.

\section{Conclusions}

In spite of the elevated carbon content, due to a rough sorting of scrap steel, the tests performed on Senegalese reinforcing steel bars reveal an acceptable metallurgical and mechanical quality. However, the only criteria taken into account, which are the chemical composition and the guaranteed minimum value for the nominal yield strength, are not sufficient to manufacture high quality armatures.

It has been shown that an excess in carbon content leads to inappropriate mechanical characteristics. The yield strength increases and the percentage of elongation at failure decreases, resulting in too brittle steel.

In particular, the hot rolling conditions and the cooling rate must be carefully observed. A too fast cooling induces microstructure transformations leading to an increase of the mechanical characteristics.

Geometrical characteristics must also be respected because compensating the yield strength increase with a decrease of the armature diameter in order to keep values of the nominal yield strength close to those fixed by the manufacturer, can lead to critical situations.

All these parameters should be specified in the fabrication process or could be taken into account by the Senegalese agency for normalisation.

Moreover, technical solutions exist to improve the quality of the reinforcing steel bars, but they involve modifications in the fabrication process. Refining the liquid metal after melting in the electric furnace would permit to increase the amount of recycled scrap, as cast iron could be treated. 
Decarburisation in solid phase is another possible process, but it is very expensive due to the current cost of energy in Senegal.

That is why a simple method, deriving from the analysis of industrial products, is proposed to evaluate the quality of steel intended to produce reinforcing bars with desired yield strength and geometrical characteristic. This method, based on Vickers hardness measurements, takes into account European specifications which are more severe than those currently applied in Senegal.

Beyond its technical interest, this research comes within the scope of environmental questions and sustainable development that concern more and more countries, including developing countries.

\section{Acknowledgement}

The authors thank SOSETRA (Mr A. NIANG) for providing the samples and for helpful discussions. They also thank AUF (Agence Universitaire de la Francophonie) for financial support.

\section{References}

[1] Kankam C K, Adom-Asamoah M. Strength and ductility characteristics of reinforcing steel bars milled from scrap metals. Mater and Des 2002;23:537-45.

[2] Young M L, Almer J D, Daymond M R, Haeffner D R, Dunand D C. Load partitioning between ferrite and cementite during elasto-plastic deformation of an ultrahigh-carbon steel. Acta Mater 2007;55:1999-2011.

[3] Elliot R A, Orowan E, Udoguchi T, Argon A S. Absence of yield points in iron on strain reversal after aging, and the Bauschinger overshoot. Mech Mater 2004;36:1143-53.

[4] Kumar A, Singh S B, Ray K K. Influence of bainite and martensite content on the tensile properties of low carbon dual phase steels. Mat Sci Eng A-Struct 2007;in press.

[5] Ashby M F, Jones D R H. Engineering Materials 1, $3^{\text {rd }}$ ed. Butterford Heinemann, 2005.

[6] Il'ina V P. Effect of surface decarburization on the susceptibility of high strength steel 38Kh5MFSA to brittle fracture. Met Sci Heat Treat;1999;41:18-9.

[7] Newby J, Mills K. Metals Handbook: Metallography and Microstructures. 9th ed.:ASM International; 1989 .

[8] Fruehan R J. The Making, Shaping and Treating of Steel. Steelmaking and Refining Volume. 11th ed.:United States Steel Corp; Aise Steel Foundation ;1998.

[9] Tabor D. The hardness of solids. Review of Physics in Technology. 1970;1:145-79. 